\title{
Deferiprone versus Deferoxamine in Sickle Cell Disease: Results from a 5-year long-term Italian multi-center randomized clinical trial.
}

\author{
Giusi Calvaruso \\ Unita'Operativa Complessa Ematologia II, A.O.R. Villa Sofia-V. Cervello
}

Angela Vitrano

Dipartimento di Scienze Economiche, Aziendali e Statistiche, Università di Palermo

Rosario Di Maggio

Unita'Operativa Complessa Ematologia II, A.O.R. Villa Sofia-V. Cervello

Eిalnaiv KhiBaHådditional works at: https://jdc.jefferson.edu/cardeza_foundation

T' omas Jefferson University

Part of the Hematology Commons

Mertinutsthintors how access to this document benefits you Center of Excellence in Sickle Cell Disease, Department of Pediatrics, Pathology and Laboratory Medicine, Boston Medical Center

\section{Recommended Citation}

Calvaruso, Giusi; Vitrano, Angela; Di Maggio, Rosario; Ballas, Samir K.; Steinberg, Martin H; Rignext Bagefo; or additional authors Aurelio, "Deferiprone versus Deferoxamine in Sickle Cell Disease: Results from a 5-year longterm Italian multi-center randomized clinical trial." (2014). Cardeza Foundation for Hematologic Research. Paper 10.

https://jdc.jefferson.edu/cardeza_foundation/10

This Article is brought to you for free and open access by the Jefferson Digital Commons. The Jefferson Digital Commons is a service of Thomas Jefferson University's Center for Teaching and Learning (CTL). The Commons is a showcase for Jefferson books and journals, peer-reviewed scholarly publications, unique historical collections from the University archives, and teaching tools. The Jefferson Digital Commons allows researchers and interested readers anywhere in the world to learn about and keep up to date with Jefferson scholarship. This article has been accepted for inclusion in Cardeza Foundation for Hematologic Research by an authorized administrator of the Jefferson Digital Commons. For more information, please contact: JeffersonDigitalCommons@jefferson.edu. 


\section{Authors}

Giusi Calvaruso, Angela Vitrano, Rosario Di Maggio, Samir K. Ballas, Martin H Steinberg, Paolo Rigano, Massimiliano Sacco, Paul Telfer, Disma Renda, Rita Barone, and Aurelio Maggio 


\title{
Deferiprone versus Deferoxamine in Sickle Cell Disease: results from 5-year long-term Italian multi-center. randomized clinical trial
}

\author{
Giusi Calvaruso ${ }^{1}$, Angela Vitrano ${ }^{2}$, Rosario Di Maggio ${ }^{1}$, Samir \\ Ballas $^{3}$, Martin H. Steinberg ${ }^{4}$, Paolo Rigano ${ }^{1}$, \\ Massimiliano Sacco ${ }^{1}$, Paul Telfer ${ }^{5}$, Disma Renda ${ }^{1}$, Rita Barone ${ }^{1}$, \\ and Aurelio Maggio and the Investigators of the Multicenter \\ Randomized Clinical Trial of Deferiprone versus Deferoxamine in \\ Sickle-Cell-Disease
}

\begin{abstract}
${ }^{1}$ Unita'Operativa Complessa Ematologia II, A.O.R. Villa Sofia - V. Cervello, Palermo, Italy

${ }^{2}$ Dipartimento di Scienze Economiche, Aziendali e Statistiche, Università di Palermo, Palermo, Italy

${ }^{3}$ Division of Hematology/Cardeza Foundation, Department of Medicine , Jefferson Medical College, Thomas Jefferson University, Philadelphia, Pennsylvania, United States of America

${ }^{4}$ Center of Excellence in Sickle Cell Disease, Pediatrics, Pathology and Laboratory Medicine, Boston Medical Center, Boston, Massachusetts, United States of America

${ }^{5}$ Department of Hematology, The Royal London Hospital, London, United Kingdom
\end{abstract}

Corresponding author's name and contact information: Aurelio Maggio, U.O.C. “Ematologia II , A.O. R.'Villa Sofia - V. Cervello', Via Trabucco $\mathrm{n}^{\circ} 180,90143$ Palermo, Italy. Phone: 00390916885251, Fax: 00390916802895,E-mail: md.amaggio@gmail.it 


\section{Summary}

Blood transfusion and iron chelation currently represents a supportive therapy to manage anaemia, vasculopathy and vaso-occlusion crises in Sickle-Cell-Disease.

Here we describe the first 5-years long-term randomized clinical trial comparing Deferiprone versus Deferoxamine in patients with Sickle-Cell-Disease. The results of this study show that Deferiprone has the same effectiveness as Deferoxamine in decreasing body iron burden, measured as repeated measurement of serum ferritin concentrations on the same patient over 5-years and analyzed according to the linear mixed-effects model (LMM) $(p=0.822)$.

Both chelators are able to decrease, significantly, serum ferritin concentrations, during 5-years, without any effect on safety $(p=0.005)$. Moreover, although the basal serum ferritin levels were higher in transfused compared with non transfused group $(p=0.031)$, the changes over time in serum ferritin levels was not statistically significant different between transfused and non-transfused cohort of patients $(p=0.389)$.

Kaplan-Meier curve, during 5-years study, suggests that Deferiprone does not alter survival in comparison with Deferoxamine $(p=0.38)$.

In conclusion, long-term iron chelation therapy with Deferiprone was associated with efficacy and safety similar to that of Deferoxamine. Therefore, in patients with Sickle-Cell-Disease, Deferiprone may represent an effective long-term treatment option.

Key points: Chelation in Sickle-Cell-Disease, Effectivenes of Deferiprone in SickleCell-Disease, DFP versus DFO in Sickle-Cell-Disease 


\section{Introduction}

Blood transfusion currently represents a supportive therapy to manage anaemia, vasculopathy and sickle vaso-occlusion. In adults, aggressive transfusion to treat and improve organ dysfunction is used [1,2] more frequently and chronic transfusion therapy significantly reduces the risk of primary and secondary stroke in paediatric patients with Sickle- Cell-Disease (SCD) [3,4].Therefore, transfusional iron overload has been associated with morbidity and mortality in SCD [5].

Patients with SCD show differences in iron metabolism and trafficking compared with other haemoglobinopathies. Particularly, the effects of inflammatory cytokines in SCD may lead to increased iron levels in reticuloendothelial, macrophage and renal cells, resulting in different tissues and organs being affected by iron overload in SCD compared with $\beta$ thalassaemia [6]. Moreover, urinary loss of iron from intravascular haemolysis and lower levels of Non-Transferrin-Bound-Iron (NTBI) due to inflammation may contribute to the different patterns of iron overload [7].

Regularly transfused patients with SCD still have increased liver iron concentration (LIC), which has been shown to correlate significantly with the volume and duration of transfusions. Increased LIC is also associated with liver fibrosis [8$10]$.

As a result, guidelines currently recommend initiating iron chelation therapy in patients with SCD once LIC increases to $>7 \mathrm{mg}$ Fe/g dry weight, if steady state serum ferritin levels are $>1000 \mathrm{ng} / \mathrm{l}$, or if patients have received cumulative transfusions of $120 \mathrm{cc}$ packed red blood cells/kg [1] or at least 20 units of blood transfusions [11]. Safety and effectiveness of iron chelation in SCD has been reported only in a large prospective clinical trial of Deferasirox (DFX) where patients with SCD completing a 1-year, Phase II, randomized, Deferoxamine (DFO)controlled study [12] entered a 4-year extension, continuing to receive DFX, or switching from DFO to DFX [13].

However, long-term safety and effectiveness findings in SCD have not been reported from randomized clinical trials comparing oral chelation with DFO. Moreover, no data on long-term Deferiprone (DFP) safety and efficacy of DFP treatment in SCD has been reported.

Therefore, we conducted a 5-year-trial of DFP versus DFO in Italian population with SCD to assess the impact of these two chelators on serum ferritin concentrations, safety, costs and survival analysis in patients with SCD. 


\section{Materials and methods}

Design

The trial was a 5-year multicenter randomized open-label trial with blinded data management and data analyses, to assess whether either treatment was superior to the other.

The trial was performed on behalf of the Italian Society for the Study of Thalassaemia and Haemoglobinopathies (SoSTE) (http://www.soste.org).

The investigators initiated, carried out, and controlled the trial, which was conducted without the influence of the sponsor [14]. Other 5-years of follow-up after the end of the trial was planned. The trial was registered at http://www.clinicaltrials.gov, Identifier NCT00733811.

\section{Patients}

Consecutive SCD patients observed at 9 centers in Italy between January 2001 and May 2011 were eligible for the trial if they had a serum ferritin concentration between 800 and $3000 \mathrm{ng} / \mathrm{ml}$ and were over 13 years of age.

Parents gave informed consent for patients between 13 and 18 years of age. The data were collected at the coordinating centre (A.O.V. Cervello, U.O.C. di Ematologia II, Palermo, Italy).

The diagnosis of SCD was based on accepted clinical and molecular criteria [15]. The exclusion criteria were (i) known intolerance to one of the trial treatments, (ii) platelet count $<100,000 / \mu 1$ or leucocyte count $<3000 / \mu 1$ (iii) severe liver damage as indicated by Child-Plugh $\mathrm{C}$ grade classification, (iv) sepsis at entry and (v) overt heart failure. Eligibility and exclusion criteria were checked at each participating centre, where the patients were also seen throughout the entire follow-up period.

If the patients were treated with subcutaneous (sc) administration of DFO (30$50 \mathrm{mg} / \mathrm{kg}$ per day, $8-12 \mathrm{~h}$ for $5 \mathrm{~d}$ a week) before inclusion in the trial, wash-out from DFO for 1 week was performed before randomization after verifying inclusion and exclusion criteria. The same timing was used if the patient was on DFX and randomized to DFO. Figure 1 shows the trial profile.

\section{Randomization}

The randomization sequence was based on a computer randomized list in permuted blocks of 10 with a 1:1 ratio, generated at the Department of Scienze Economiche, Aziendali e Statistiche of the University of Palermo, Italy. To ensure allocation concealment, treatment was assigned by telephone contact from the coordinating center. The sequence was concealed until interventions were assigned.

Randomization was performed for each consecutive patient after verification of the exclusion criteria. Treatment was started within the following $24 \mathrm{~h}$. Patients 
visited the clinic monthly where clinical and predefined data forms were collected. The data were regularly forwarded to the coordinating center, where a complete database for all included patients was established.

\section{Interventions}

Trial interventions were DFP (Apotex; Toronto, ON, Canada) at $75 \mathrm{mg} / \mathrm{kg} / \mathrm{day}$, divided into three oral daily doses, for $7 \mathrm{~d}$ /week versus DFO (BiofuturaPharma, Pomezia, Italy) by sc infusion $(8-10 \mathrm{~h})$ at $50 \mathrm{mg} / \mathrm{kg}$ per day for $5 \mathrm{~d} /$ week A doubleblinded design was not considered to be possible because of the sc administration of DFO. The planned duration of treatment was 5 years.

During this period, treatment was only interrupted at the discretion of the investigators if needed for intercurrent illness or adverse events (AEs). Count blood cell was performed weekly for monitoring, according to the manufacturing recommendations for DFP.

Dose modifications were allowed for safety reasons. Criteria for dosage reduction treatment to DFP $50 \mathrm{mg} / \mathrm{kg}$ per day were arthralgia and nausea not controlled by symptomatic therapy and for reduction treatment to DFO $30 \mathrm{mg} / \mathrm{kg}$ per day were local reactions at the site of infusion. Both treatments were reduced if the ferritin levels on two consecutive determinations were less than $400 \mathrm{ng} / \mathrm{ml}$. Treatment was restarted when ferritin levels were greater than $700 \mathrm{ng} / \mathrm{ml}$ on at least two determinations.

Treatment failure was defined as an increase of serum ferritin levels more than 1000ng /ml from baseline, confirmed in at least two consecutive determinations. Patients who failed were switched to the alternative treatment and followed until the end of the study.

All outcome assessments were coded by physicians blinded to the trial treatment. Drug administration was recorded on the case report form. Assessments for safety and efficacy were performed at monthly planned follow-up visits.

Compliance was assessed by counting the pills in each returned bag of DFP and by assessing the number of infusions of DFO registered on the electronic pump (CronoTM, Gene S.r.l., Italy).

\section{Primary and secondary outcomes}

The primary end point of treatment efficacy was the change from the baseline value in serum ferritin levels during the 5 years. Secondary endpoints were safety and survival analysis at 5-years.

\section{Follow-up after the trial}

Other 5-years of follow-up, after the end of the trial, was planned to collect 
data on survival about this cohort of patients. During this period patients were allowed to change chelation. Data about causes and chelation treatment at death were collected during this period.

\section{Sample size estimation}

Sample size estimation for the two treated groups was performed taking into account repeated measures as discussed in Rochon [16]. For our study, the recommended number of subjects was between 40 and 100 .

A minimum number of patients required in each treatment group was calculated assuming equal allocation, under the hypothesis of equality between the two treatment groups at every point during the course of the trial for the autoregressive correlation structure, for a two-sided test at $\alpha=0.05, \beta=0.80, \Delta=0.41$ (standardized effect), $\rho=0.60$, and number of follow-up measurements $\mathrm{T}=5$.

Costs

The costs of chelation treatments were calculated for the overall period of observation based on cost for 1-day treatment per each person multiplied by the person-years of treatment.

Periods of reduced dosage were also considered for the cost analysis. The cost data were obtained by the Italian Ministry of Health.

\section{Ethics}

The study was conducted according to the Declaration of Helsinki (http://www.wma.net/e/policy/b3.html) and was approved by the local Institutional Review Board (IRB) of each participant center.

The patients (or the parents of minors) gave their written informed consent to participate in the trial. Trial was conducted according to GMP and the EU clinical trials directive.

\section{Statistical methods}

All descriptive and inferential statistical analyses were performed under code of the Department of Scienze Economiche, Aziendali e Statistiche from the University of Palermo, by a statistician (A. V.) blinded to the trial interventions, using STATA 12.0 software (StataCorp, College Station, TX, USA).

Statistical significance is declared when the $p$-value is less than 0.05. All statistical tests are two-sided. For the purpose of statistical analyses, missing scores were not included. Thus, observed case analyses have been employed for efficacy determinations.

Baseline descriptive statistics were presented for each variable. Specifically, for categorical variables, the number and the percent of each category within a 
parameter were calculated for non-missing data, and difference in the two treatment arms was compared using a Fisher's exact test. For continuous variables, the mean, standard deviation values were derived, and the comparisons between the baseline mean difference in the two intervention groups were based on a t-test.

Data on serum ferritin levels consists of repeated measurement on the same patient over time. For the purpose of the study a linear mixed-effects model (LMM) was used [17]. A mixed model analysis in such a study does not require complete data from all subjects. This results in more appropriate estimates of the effect of treatment and their standard errors. The analysis was based on a LMM where the patient effect (given by the intercept terms for each patient) was regarded as random effect, while the treatment effect (treat), the time effect (time), the treatment-by-time interaction effect (treat $\times$ time), and the total transfutions in $\mathrm{ml}$ (tot TX) were regarded as fixed effects. In developing this model, the fact that measurements taken on the same patient may not be independent of one another, was taken into account. In this context, an autoregressive correlation of order 1, AR (1) structure, was considered to model correlation within repeated observations. The same analysis (LMM) was applied to look at possible statistical significant difference between transfused and non-transfused SCD group.

The Kaplan-Meier method was used to estimate survival probability for the two treated groups of the randomized patients. The survival curves were compared per treatment group using the log-rank test. Survival analysis was performed from January 30, 2001 to January 30, 2006. Data about causes and chelation at death, after 5 -years from the end of the study was collected and reported.

\section{Results}

\section{Participant recruitment and flow}

Consecutive SCD patients $(\mathrm{n}=94)$ between January 30,2001 and January 30, 2006 were considered to be eligible for the trial (Fig 1).

Four patients did not meet inclusion criteria and 30 patients declined to participate (Fig 1). The remaining 60 patients were included; 30 and 30 respectively, were randomly allocated to DFP versus DFO treatment (Fig 1). No patients were lost to follow-up.

\section{Baseline data}

Hematological and clinical findings at enrolment are shown in Table 1. No differences were observed at baseline between the two randomized groups (Table 1).

Particularly, the degree of iron overload, expressed by serum ferritin at baseline, and the amount of blood transfusions requirement, were similar in the two groups (Table 1). Therefore, these findings suggest that severity of body iron burden was similar between the two groups (Table 1). 


\section{Serum ferritin concentrations}

Table 2 shows baseline and follow-up mean serum ferritin values during the 5year treatment.

Table 3 shows results of statistical modelling process to evaluate efficacy of DFP versus DFO treatment based on repeated measures of serum ferritin values during the study period.

Figure 2 shows the fitted effects of serum ferritin levels in the two treatment groups. Cases of patients with serum ferritin levels $<400 \mathrm{ng} / \mathrm{ml}$ were detected. The incidence of patients with serum ferritin levels $<400 \mathrm{ng} / \mathrm{ml}$ was higher in the DFP group (11 patients, 36.6\%) in comparison with the DFO group (1 patient, 3.3\%). This difference was statistically significant ( $p$-value $=0.002$ ).

Transfused and non-transfused patients with SCD showed significant changing over time in serum ferritin levels $(p=0.029)$ (Table 4). Moreover, although the basal serum ferritin levels were higher in transfused compared with non transfused group $(p=0.031)$, the changes over time in serum ferritin levels was not statistically significant different between the two cohorts of patients $(p=0.389)$ (Table 4).

\section{Adverse events and treatment failure}

Table 5 reports the main side effects in the two groups. The overall period of observation was 192 person-years for DFP patients compared with 196 person- years for DFO patients.

Sixteen subjects in the DFP and 13 in the DFO group withdrew definitely from the trial (Table 5). The mean time for definitive withdrawal was $77.7 \pm 93.8$ (days) in the DFP group versus $191.4 \pm 153$ (days) in the DFO group respectively. There was no statistically significant difference in temporary and definitive discontinuation of treatment between the groups $(p=0.764)$ during the overall period of observation.

Dosage decrease was necessary in 2 of DFP patients versus 1 of DFO patients. There was only one case of treatment failure in the DFO group and no case in DFP group.

No patients with agranulocytosis were reported in the DFP-treated group (Table 5). Nine and seven patients received hydroxycarbamide during DFP and DFO chelation treatment, respectively. 
Survival analysis was extended for the 5-years of the trial (Fig. 3). The KaplanMeier survival probability curves of the two treatment groups are reported on Fig. 3. The intention-to treat analysis did not show any statistically significant difference between the two groups (Fig. 3; $p=0.38$ ). The causes of death for single chelation treatment are reported on Table 6.

\section{Follow-up after the trial}

Data about causes and chelation treatment at death, after 5-years from the end of the study, are reported on Table 7. Kaplan-Meier survival probability at 10-years (graph not shown) did not show any statistically significant difference between the two groups $(p=0.88)$.

\section{Compliance and costs}

In the DFP group, compliance was $89 \%$, while with DFO was $75 \%$. The calculated mean \pm SD cost was $4581 \pm 1598$ Euros per person-year (range 983 6209) for DFP treatment versus $4966 \pm 2117$ Euro per person-year (range 488 $7352)$ for DFO treatment. This difference was not statistically significant $(p=0.43)$.

\section{Discussion}

The increased life expectancy of patients with SCD has led to a need for longterm iron chelation therapy to prevent the onset of complications associated with iron overload, but long-term iron chelation data in SCD are currently limited to DFX.

The current study is the only study to date to assess the long-term efficacy and safety of DFP, during a long-term randomized clinical trial in patients with SCD. The results of this study show that DFP has the same effectiveness as DFO in decreasing serum ferritin concentration, without increasing adverse events or costs.

In a prospective clinical trial of 15 patients with SCD, Voskaridou et al. [18] concluded that DFP decreased the serum ferritin levels significantly in 10/12 (83.3\%) subjects who completed the study. Treatment with deferiprone was not associated with any major side effects in this study. Particularly, there was no evidence of change in the liver function and no cytopenias, and only one patient had severe gastrointestinal side effects.

Collins et al., 1994 [19] suggested as the mean daily urinary iron excretion induced by DFP at $75 \mathrm{mg} / \mathrm{kg} / \mathrm{d}(0.48 \pm 0.23 \mathrm{mg} / \mathrm{kg})$ was equivalent to that induced by DFO at $50 \mathrm{mg} / \mathrm{kg} / \mathrm{d}(0.39 \pm 0.06 \mathrm{mg} / \mathrm{kg})$.

Our findings from a long-term, multicenter, randomized clinical trial 
demonstrate that DFP was not inferior to DFO in the treatment of iron overload in patients with SCD.

Serum ferritin levels showed a linear decrease over time in both treatment groups but the mean changes of serum ferritin levels over time did not differ between the two treated groups. Moreover, applying the linear mixed-effects model (LMM) to model serum ferritin in transfused versus non-transfused SCD enrolled patients, there was not statistical significant difference in changing over the time of serum ferritin levels between these two cohorts of patients $(p=0.389)$ (Tab. 4), although the basal serum ferritin levels were higher in transfused compared with non-transfused group ( $p=0.031$ ) (Tab. 4). This last finding is similar to that reported by Brown et al., 2009 [10] who showed relationship between hepatic iron content and the transfusion volume in 27 children with sickle cell anemia receiving chronic transfusion therapy [10] .

The incidence of adverse events was similar between the two treated groups, with treatment refusal and local reactions the main adverse events during DFO treatment. Although the number of DFP treated patients was limited, the lack of agranulocytosis, in DFP treated patients, during an overall period of observation of 192 person-years may be meaningful. An incidence of agranulocytosis ranging from 0.4 to $0.6 / 100$ person-years, as reported for patients with thalassemia major treated with DFP [20,21], might have led to at least one case of agranulocytosis in the present trial. Previous trials on DFP in SCD patients did not suggest any effects on liver function nor did they report agranulocytosis $[18,22,23]$. Nine patients enrolled on DFP arm also received hydorxycarbamide for prevention of SCD crises. The lack of agranulocytosis, during simultaneous treatment with DFP and hydroxycarbamide, was previously reported, and the current study increases the number of patients treated with DFP and hydroxycarbamide who did not develop agranulocytosis [24]. These findings suggest that the risk of agranulocytosis may be acceptable in SCD patients treated with DFP.

Compliance was better with DFP (89\%) in comparison with DFO treatment $(75 \%)$ as suggested by previous clinical trials in thalassemia major patients [25] . Moreover, a similar low compliance was observed in several shorter-term SCD clinical trials of hydroxyurea [26-28] and during DFX long-term safety and efficacy study [13], suggesting that disease and social factors specific to SCD patient populations may contribute substantially to low study completion rates [13].

The cost analysis did not show a statistical significant difference between the two treatment groups $(p=0.43)$.

The results of survival curves, during the trial, even suggest that DFP does not alter survival in comparison with DFO (Fig. 3). The causes of death in this study were not related to iron overload or chelation therapy but were similar to those found in the natural history of SCD [29] (Table 6). These findings are confirmed at the follow-up after 5-years from the end of the trial (Tab. 7).

The limit of the study could be that serum ferritin levels in patients with SCD have shown varying degrees of correlation with LIC, which is considered a more direct measure of iron overload, especially in pediatrics patients [30,31].However, the 
design of the study as randomized clinical trial, the effectiveness of treatment evaluated at repeated measurement on the same patient over time of serum ferritin levels and the inclusion in the trial of a large cohort of adult patients, may surely have balance effect on this bias.

In conclusion, long-term iron chelation therapy with DFP was associated with efficacy and safety similar to that of DFO. Therefore, in patients with SCD, DFP may represent an effective long-term treatment option to accompany on-going transfusion therapy, reducing the risk of developing complications of iron overload.

These findings, together with those reported for deferasirox[12,13], suggest that oral chelation could be now a reasonable choice for the management of iron overload in patients with SCD. 


\section{Acknowledgements}

The authors are grateful for their support to the patients and families who participated in this study. The suggestions and advices of Prof. Alan Cohen were greatly appreciated. The partial support of Foundation Franco and Piera Cutino was greatly appreciated.

\section{Authorship}

Contribution: GC provided study and patient data, contributed to data analysis and interpretation and wrote the manuscript, AV performed statystical analysis, RDM edited the manuscript, MS contributed to statystical analysis, DR,RB and PR contributed to patient data, AM contributed to the design and interpretation and wrote the manuscript, SB,MHS,AC,PT reviewed the manuscript, other authors provided patient data.

Conflict-of-interest: the authors declare no competing financial interests.

Correspondence: Aurelio Maggio, U.O.C. "Ematologia II , A.O. R.”Villa Sofia - V. Cervello", Palermo, Italy. E-mail: md.amaggio@gmail.it

\section{Appendix}

The following institutions and investigators participated in the Multicenter Randomized Clinical Trial of Deferiprone versus Deferoxamine in Sickle Cell Disease: Clinical Centers (the numbers in parentheses are the numbers of patients enrolled at each center) - Centro per la Talassemia e l'Anemia Falciforme, Azienda Sanitaria Provinciale di Caltanissetta Vittorio Emanuele, Gela, Caltanissetta, Italy (53): Alessandra Quota and Ketty Perrotta; Unità Operativa Complessa Ematologia II , A.O.R. Villa Sofia - V. Cervello, Palermo, Italy (17): Antonino Giangreco and Veronica Di Salvo; Centro per la Talassemia, Azienda Ospedaliera Universitaria Policlinico Vittorio Emanuele - Santo Bambino, Catania, Italy (9): Turi Lombardo and Gaetano Giuffrida; Unità Operativa Complessa di Pediatria, Ospedale Galliera, Genova, Italy (6): Gianluca Forni; Unità Operativa Semplice Dipartimentale, Azienda Ospedaliera S. Eugenio, Roma, Italy (3): Paolo Cianciulli; Unità Operativa Complessa di Medicina Trasfusionale, Azienda Ospedaliera M. Paternò Arezzo, Ragusa, Italy (3): Carmelo Fidone; Unità Operativa Semplice di Talassemia, Presidio Ospedaliero S. Agata di Militello, Italy (2): Gaetano Roccamo; Unità Operativa Complessa di Pediatria, Azienda Ospedaliera S. Antonio Abbate, Trapani, Italy (1): Antonella Carollo 


\section{References}

1) National Institutes of Health NHLBI. The management of sickle cell disease. 2002. NIH Publication No 02-2117. Available http://www.nhlbi.nih.gov/health/prof/blood/sickle/sc_mngt.pdf. Accessed 28 October 2010

2) Wun, T, Hassell, K. Best practices for transfusion for patients with sickle cell disease. Hematology Reports. 2009;1:e22.

3) Adams RJ, McKie VC, Hsu L, et al. Prevention of a first stroke by transfusions in children withkle cell anemia and abnormal results on transcranial Doppler ultrasonography. N Engl J Med. 1998 Jul 2;339(1):511.

4) Adams RJ, Brambilla D. Optimizing Primary Stroke Prevention in Sickle Cell Anemia (STOP 2) Trial Investigators Discontinuing prophylactic transfusions used to prevent stroke in sickle cell disease. $\mathrm{N}$ Engl J Med. 2005 Dec 29;353(26):2769-78.

5) Ballas SK . Iron overload is a determinant of morbidity and mortality in adult patients with sickle cell disease. Semin Hematol. 2001 Jan;38(1 Suppl 1):30-6.

6) Walter PB, Harmatz P, Vichinsky E. Iron metabolism and iron chelation in sickle cell disease. Acta Haematol. 2009;122(2-3):174-83. doi:

10.1159/000243802. Epub 2009 Nov 10.

7) Schein A, Enriquez C, Coates TD, Wood JC.Magnetic resonance detection of kidney iron deposition in sickle cell disease: a marker of chronic hemolysis. J Magn Reson Imaging. 2008 Sep;28(3):698-704. doi: 10.1002/jmri.21490.

8) Harmatz P, Butensky E, Quirolo K, et al. Severity of iron overload in patients with sickle cell disease receiving chronic red blood cell transfusion therapy. Blood. $2000 \mathrm{Jul}$ 1;96(1):76-9.

9) Olivieri NF. Progression of iron overload in sickle cell disease. Semin Hematol. 2001 Jan;38(1 Suppl 1):57-62.

10) . Brown K, Subramony C, May W, et al. Hepatic iron overload in children with sickle cell anemia on chronic transfusion therapy. J Pediatr Hematol Oncol. 2009 May;31(5):309-12.

11) Sickle Cell Society. Standards for the clinical care of adults with sickle cell disease in the UK. 2008. Available at:

http://www.sicklecellsociety.org/pdf/CareBook.pdf. Accessed 28 October 2010.

12) Vichinsky E, Onyekwere O, Porter J, et al. A randomised comparison of deferasirox versus deferoxamine for the treatment of transfusional iron overload in sickle cell disease. Br J Haematol. 2007 Feb;136(3):501-8.

13) Vichinsky E, Bernaudin F, Forni GL, et al. Long-term safety and efficacy of deferasirox (Exjade) for up to 5 years in transfusional ironoverloaded 
patients with sickle cell disease. Br J Haematol. 2011

Aug;154(3):387-97.

14) Maggio A, D'Amico G, Morabito A .Independent clinical trials.

Lancet. 2004 Mar 27;363(9414):1080.

15) Maggio A, Giambona A, Cai SP et al. Rapidand simultaneous typing of hemoglobin S, hemoglobin C, and seven Mediterranean beta-thalassemia mutations by covalent reverse dot-blot analysis: application to prenatal diagnosis in Sicily. Blood. 1993 Jan 1;81(1):239-42.

16) Rochon, J. Sample size calculations for two-group repeated measures experiments. Biometrics1191; 47, 1383-1398.

17) Laird NM, Ware JH. Random-effects models for longitudinal data. Biometrics. 1982 Dec;38(4):963-74.

18) Voskaridou E, Douskou M, Terpos E, et al. Deferiprone as an oral iron chelator in sickle cell disease. Ann Hematol. 2005 Jul;84(7):434-40. Epub 2005 Apr 5.

19) Collins AF, Fassos FF, Stobie $S$, et al. Iron-balance and dose-response studies of the oral iron chelator 1,2-dimethyl-3-hydroxypyrid-4-one (L1) in iron-loaded patients with sickle cell disease. Blood. 1994 Apr $15 ; 83(8): 2329-33$.

20) Cohen AR, Galanello R, Piga A, Dipalma A, Vullo C, Tricta F. Safety profile of the oral iron chelator deferiprone: a multicentre study. Br J Haematol. 2000 Feb;108(2):305-12.

21) Ceci A, Baiardi P, Felisi M, et al. The safety and effectiveness of deferiprone in a large-scale, 3-year study in Italian patients. Br J Haematol. 2002 Jul;118(1):330-6.

22) Hoffbrand, A.V., AL-Refaie, F., Davis,et al. Long-term trial of deferiprone in 51 transfusion-dependent iron overloaded patients. Blood, 1991, 295-300.

23) Tsironi M, Polonifi K, Deftereos S,et al. Transfusional hemosiderosis and combined chelation therapy in sickle thalassemia. Eur J Haematol. 2005 Oct;75(4):355-8

24) Maggio A, Rigano P, D'Amico G, Mascolino A. Treatment with hydroxyurea and iron chelation therapy in patients with hemoglobinopathies. Eur J Haematol. 2005 Sep;75(3):267-9.

25) Maggio A, Vitrano A, Capra M et al. Long-term sequential deferiprone-deferoxamine versus deferiprone alone for thalassaemia major patients: a randomized clinical trial. Br J Haematol 2009 Apr;145(2):24554.

26) Charache S, Dover GJ, Moore RD, et al. Hydroxyurea: effects on hemoglobin $\mathrm{F}$ production in patients with sickle cell anemia. Blood. 1992 May 15;79(10):2555-65

27) Kinney TR, Helms RW, O'Branski EE, et al. Safety of hydroxyurea in children with sickle cell anemia: results of the HUG-KIDS study, a phase I/II trial. Pediatric Hydroxyurea Group. Blood. 1999 Sep 1;94(5):1550-4. 
28) Steinberg MH, Barton F, Castro O, et al. Effect of hydroxyurea on mortality and morbidity in adult sickle cell anemia: risks and benefits up to 9 years of treatment. JAMA. 2003 Apr 2;289(13):1645-51.

29) PerroneV, Roberts-Harewood M, Bachir D et al. Patterns of mortality in sickle cell disease in adults in France and England. Hematol J. 2002;3(1):56-60.

30) Brittenham, G.M., Cohen, A.R., McLaren, C.E. et al. Hepatic iron stores and plasma ferritin concentration in patients with sickle cell anemia and thalassemia major. American Journal of Hematology, 1993; 42, 8185 .

31) Karam, L.B., Disco, D., Jackson, S.M.et al. Liver biopsy results in patients with sickle cell disease on chronic transfusions: poor correlation with ferritin levels. Pediatric Blood Cancer, 50 2008; 62-65. 
Table 1. Baseline comparisons in the 60 patients included in the multi-center randomized clinical trial comparing Deferiprone (DFP) versus Deferoxamine (DFO) in Sickle-Cell-Disease.

\begin{tabular}{lccc}
\hline Findings & DFP & DFO & p-value \\
\hline $\mathrm{N}^{\circ}$ pts & 30 & 30 & --- \\
Females (\%) & 46.67 & 53.33 & 0.7970 \\
Age, years & $36.433 \pm 13,92$ & $35.83 \pm 11.56$ & 0.8565 \\
Age at first transfusion, years & $6.95 \pm 8.03$ & $7.81 \pm 11.94$ & 0.7605 \\
Mean age at DFo starting, years & $29.09 \pm 14.75$ & $29.77 \pm 12.03$ & 0.8593 \\
Hgb, gr/dl* & $9.59 \pm 1.68$ & $9.26 \pm 1.27$ & 0.4042 \\
ALT, IU/L* & $37.51 \pm 22.24$ & $45.97 \pm 41.67$ & 0.3395 \\
Total blood & & & \\
transfusion,(ml/year) & $2055.05 \pm 1282.01$ & $2797.15 \pm 2018.08$ & 0.1901 \\
Mean Hb pre-Tx, gr/dl & $8.99 \pm 1.32$ & $8.65 \pm 0.99$ & 0.2955 \\
Mean basal ferritin, ng/ml & $1440.14 \pm 712.7$ & $1726.03 \pm 694.01$ & 0.1274 \\
Mean basal EF (\%) & $59.91 \pm 6.65$ & $60.83 \pm 8.52$ & 0.7731 \\
Splenectomy (\%) & 45.4 & 70.6 & 0.1910 \\
Cirrhosis (\%) & 13.3 & 11.5 & 1.000 \\
Arrhythmia (\%) & 10.0 & 15.4 & 0.693 \\
HCV-RNA positive (\%) & 18.52 & 12.00 & 0.705 \\
\hline \hline
\end{tabular}


Table 2. Means of serum ferritin levels $(\mu \mathrm{g} / \mathrm{l})$ during 5-year multi-center randomized clinical trial comparing Deferiprone (DFP) versus Deferoxamine (DFO) treatment in Sickle-Cell-Disease.

\begin{tabular}{lcc} 
& DFP & DFO \\
Years & mean \pm sd (n) & mean \pm sd (n) \\
\hline Baseline & $1440.13 \pm 712.80(29)$ & $1726.03 \pm 694.01(29)$ \\
1 & $1033.00 \pm 737.41(19)$ & $1522.64 \pm 954.98(22)$ \\
2 & $1076.80 \pm 897.51(15)$ & $1100.05 \pm 798.61(19)$ \\
3 & $580.10 \pm 581.56(10)$ & $1127.68 \pm 516.42(16)$ \\
4 & $438.22 \pm 320.81(9)$ & $1078.26 \pm 356.31(15)$ \\
5 & $695.00 \pm 597.74(7)$ & $1333.85 \pm 871.74(14)$ \\
\hline \hline
\end{tabular}

Table 3. Linear Mixed Effect Model (LMM) to evaluate changes over time in mean serum ferritin levels in Deferiprone versus Deferoxamine-treated group in Sickle-Cell-Disease.

\begin{tabular}{lccccc} 
& Coefficients & SE & & $95 \% \mathrm{CI}^{*}$ & $\begin{array}{c}p- \\
\text { value }\end{array}$ \\
\hline Intercept & 1433.02 & 206.54 & & $(1028.21 ; 1837.84)$ & 0.000 \\
treat & -53.03 & 235.21 & & $(-514.02 ; 407.95)$ & 0.822 \\
time & -184.85 & 66.52 & & $(-315.23 ;-54.48)$ & 0.005 \\
treatXtime & 112.61 & 81.69 & $(-47.52 ; 272.72)$ & 0.168 \\
totTX & 0.11 & 0.05 & $(-0.01 ; 0.21)$ & 0.055 \\
\hline \hline
\end{tabular}


Table 4. Linear Mixed Effect Model (LMM) to evaluate changes over time in mean serum ferritin levels of transfused versus non-transfused patients with Sickle-Cell-Disease enrolled in the multi-center randomized trial.

\begin{tabular}{lcccc}
\cline { 2 - 5 } & Coefficients & SE & $95 \%$ CI* & $p$-value \\
\hline Intercept & $\mathbf{1 1 4 9 , 1 3}$ & $\mathbf{2 0 0 , 8 8}$ & $(\mathbf{7 5 5 . 4 2} ; \mathbf{1 5 4 2 . 8 6 )}$ & $\mathbf{0 . 0 0 0}$ \\
TX & $\mathbf{4 9 5 , 9 6}$ & $\mathbf{2 2 9 , 7 1}$ & $(\mathbf{4 5 . 7 5} ; \mathbf{9 4 6 . 1 7 )}$ & $\mathbf{0 , 0 3 1}$ \\
time & $\mathbf{- 1 7 9 , 8 1}$ & $\mathbf{8 2 , 5 4}$ & $(-341.57 ;-18.03)$ & 0,029 \\
TXxtime & $\mathbf{7 8 , 1 1}$ & $\mathbf{9 0 , 6 1}$ & $(-99.48 ; 255.70)$ & 0,389 \\
\hline
\end{tabular}

Table 5. Adverse events (AEs) in Sickle-Cell-Disease during the 5 years trial comparing Deferiprone versus Deferoxamine.

\begin{tabular}{lccccc} 
& \multicolumn{2}{c}{ DFP } & \multicolumn{2}{c}{ DFO } & \\
\cline { 2 - 6 } Adverse events & $\mathrm{N}$ & $\%$ & $\mathrm{n}$ & $\%$ & p-value \\
\hline $\begin{array}{l}\text { Local reactions at the } \\
\text { infusion site }\end{array}$ & --- & --- & 3 & 10.0 & 0.237 \\
$\begin{array}{l}\text { Fever or other } \\
\text { infections }\end{array}$ & 3 & 10.0 & --- & --- & 0.237 \\
Joint pain & 2 & 6.7 & --- & --- & 0.492 \\
Nausea & 4 & 13.3 & --- & --- & 0.112 \\
Vomit & 2 & 6.7 & --- & --- & 0.492 \\
Liver damage* & 3 & 10 & --- & --- & 0.237 \\
Treatment refusal & 1 & 3.3 & 16 & 53.3 & $<0.001$ \\
SCD crisis & 2 & 6.7 & 1 & 3.3 & 1.000 \\
Surgery & --- & -- & 2 & 6.7 & 0.492 \\
Mastitis & 2 & 6.7 & --- & -- & 0.492 \\
& & & & & \\
\hline
\end{tabular}


Table 6. Causes of death, at 5-years, in patients included in the Sickle-CellDisease multi-center randomized clinical trial comparing Deferiprone versus Deferoxamine.

\begin{tabular}{lcc}
\hline Causes of death & $\mathbf{n}(\%)$ & ${ }^{*}$ Treatment \\
\hline Acute Chest Syndrome & $1(16.7)$ & DFP \\
Respiratory failure & $2(33.3)$ & DFO \\
Hepatic failure & $3(50.0)$ & 2 DFO1DFP \\
Totals & 6 & \\
\hline \hline
\end{tabular}

*Treatment at randomization

Table 7. Causes of death, at 10-years, in patients included in the Sickle-CellDisease multi-center randomized clinical trial.

\begin{tabular}{lcc}
\hline Causes of death & $\mathrm{n}(\%)$ & ${ }^{*}$ Treatment \\
\hline Acute Chest Syndrome & $1(7,1)$ & DFO \\
Respiratory failure & $4(28,6)$ & 3 DFO, 1 DFP \\
Hepatic failure & $5(35,9)$ & DFO \\
Marasmus senile & $1(7,1)$ & DFO \\
Averse events post vaccination in liver transplant & $1(7,1)$ & DFO \\
Cardio-circulatory arrest in pulmonary hypertension & $1(7,1)$ & DFO \\
Pulmonary embolism & $1(7,1)$ & DFO \\
Totals & 14 & \\
\hline \hline
\end{tabular}

*Treatment at death. 
Figure 1. Trial profile of Deferiprone versus Deferoxamine intervention during the Sickle-Cell-Disease multi-center randomized clinical trial.

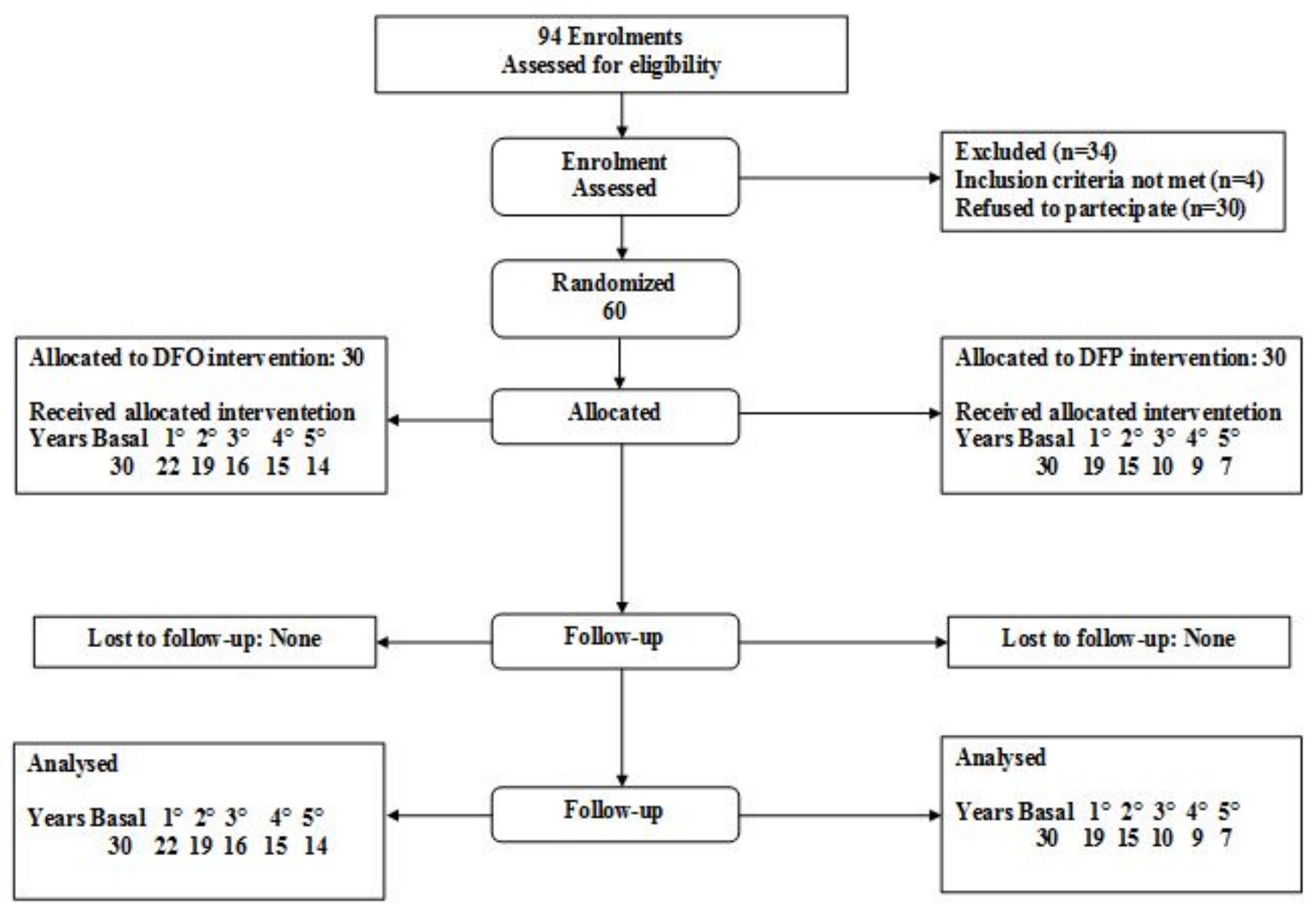


Figure 2. Estimated profiles of the mean serum ferritin in the two treatmentgroups from the fitted Linear Mixed-Effects Model (LMM) during Sickle-CellDisease multi-center randomized clinical trial.

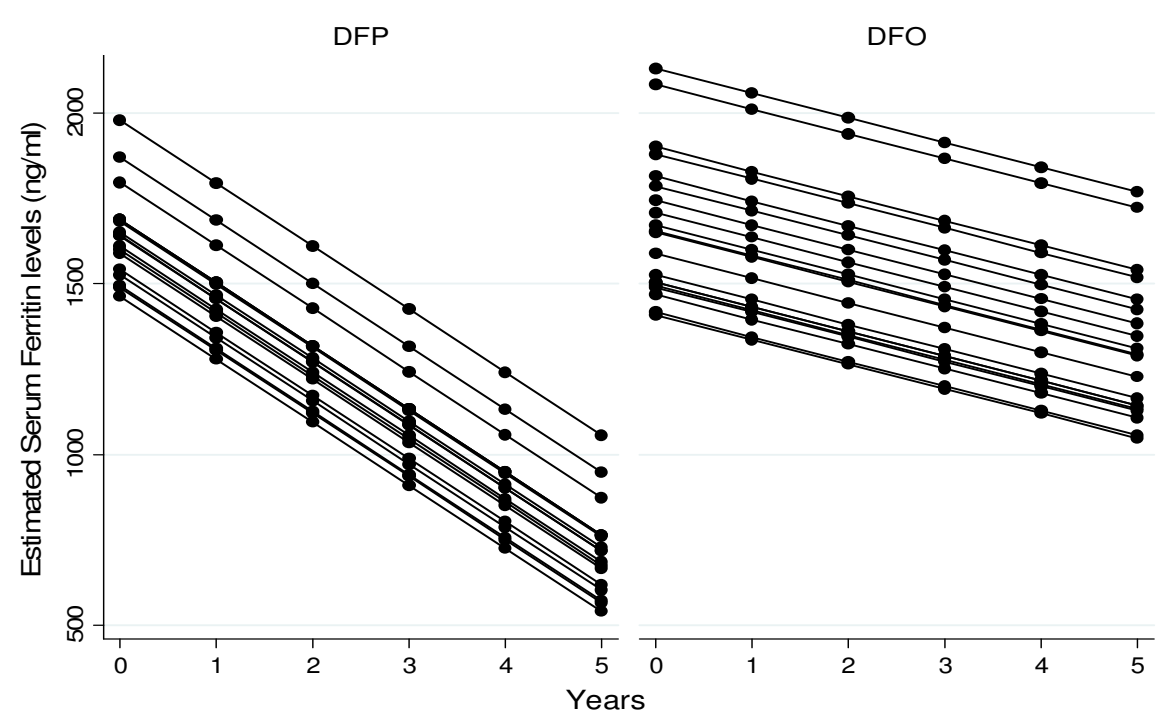


Figure 3. Kaplan-Meier survival probability curves in the two treatment groups during multi-center Sickle-Cell-Disease clinical trial (Deferiprone: continous line; Deferoxamine: dashed line) $(\mathrm{p}=0.38)$

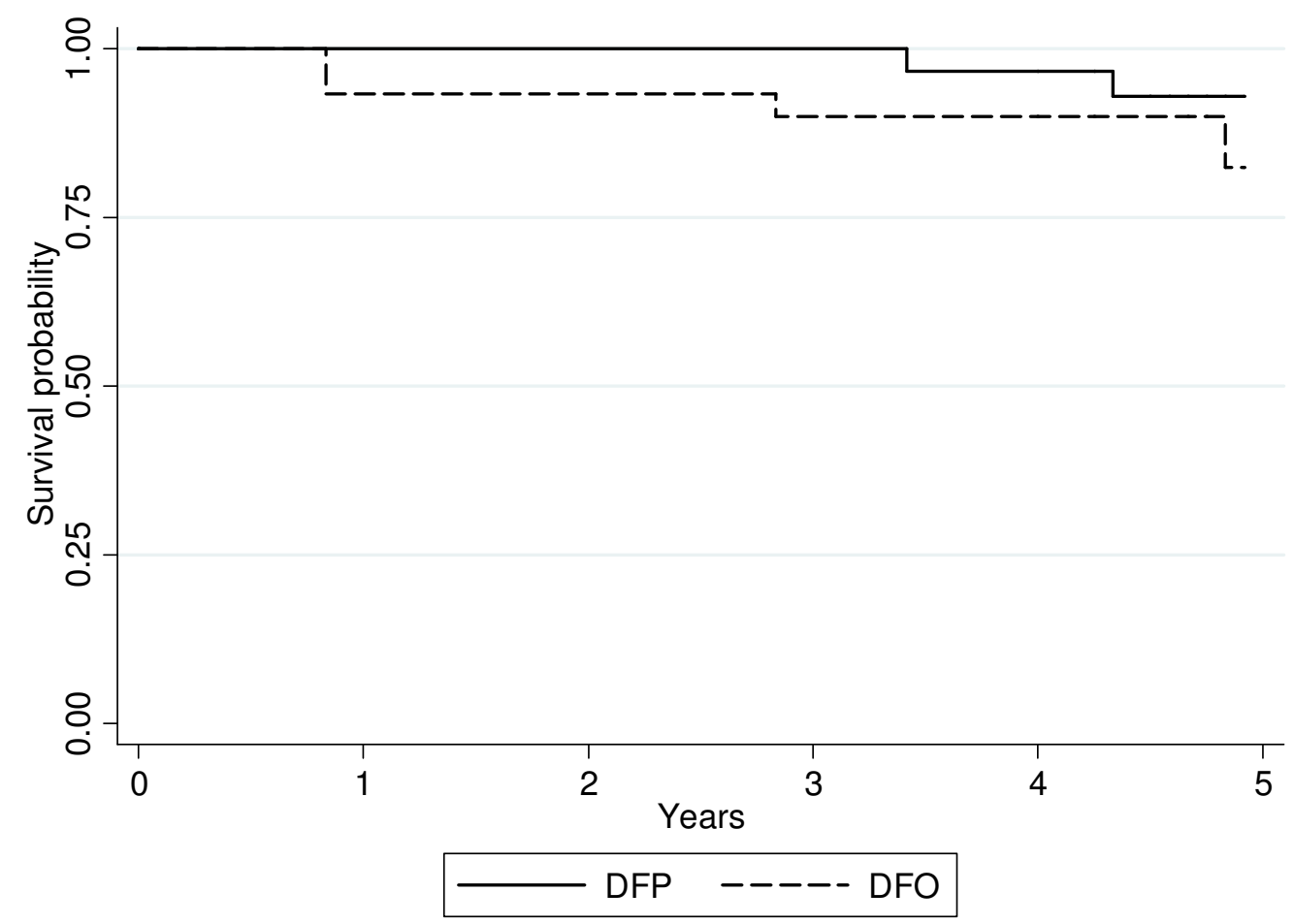

